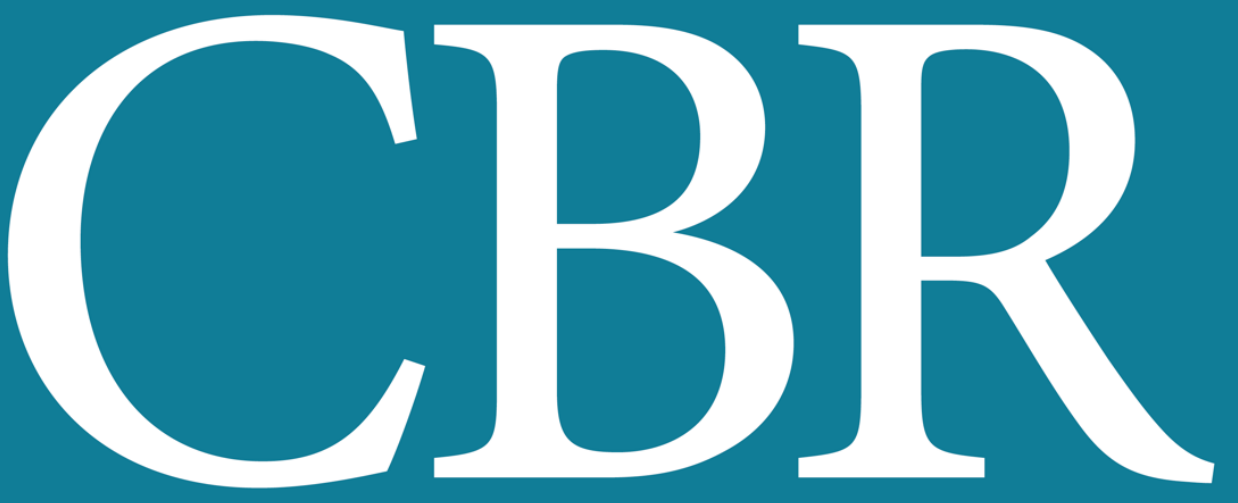

INTERNATIONAL JOURNAL OF CANCER AND BIOMEDICAL RESEARCH

https://jcbr.journals.ekb.eg

Editor-in-chief

Prof. Mohamed Labib Salem, PhD

Measurement of plasma microRNA-500 could differentiate between liver fibrosis and cirrhosis

Nahla E. El-Ashmawy, Ghada M. Al-Ashmawy, Linda A. Zayed, Ayman A. Hassan, Reham E. Soliman and Gamal E. Shiha 


\section{Welcome letter from Editor-in-Chief}

Welcome to the Int J Cancer and Biomedical Research (IJCBR)!

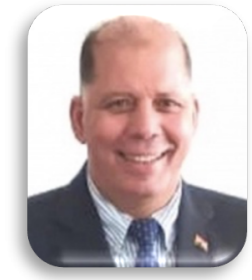

It is with great pleasure that I write this editorial to welcome you to the IJCBR. This journal provides a platform for publication of original and reviews research articles, short communications, letter to editor, thesis abstract, conference report, and case studies. These types of publication are directed at the interface of the fields of cancer and biomedical research.

The IJCBR relies on a distinguished expert of the Advisory and Editorial Board Members from the top international league covering in depth the related topics. They timely review all manuscripts and maintain highest standards of quality and scientific methodology and ethical concepts. Meanwhile, we take all possible means to keep the time of the publication process as short as possible.

I take this chance to welcome your contributions to the IJCBR and have every expectation that it will soon become one of the most respected journals in both the fields of cancer and biomedical research.

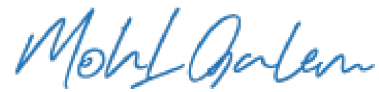

Mohamed L. Salem,

Editor in Chief 


\title{
Measurement of plasma microRNA-500 could differentiate between liver fibrosis and cirrhosis
}

\author{
Nahla E. El-Ashmawy ${ }^{1}$, Ghada M. Al-Ashmawy ${ }^{1}$, Linda A. Zayed ${ }^{2}$, Ayman A. Hassan ${ }^{3}$, Reham E. Soliman ${ }^{4}$ and \\ Gamal E. Shiha ${ }^{5}$ \\ ${ }^{1}$ Biochemistry Department, Faculty of Pharmacy, Tanta University, Egypt \\ ${ }^{2}$ Clinical Trial Unit \& Bioequivalence Center, Egyptian Liver Research Institute and Hospital, Egypt \\ ${ }^{3}$ Molecular Biology Unit at Egyptian Liver Research Institute and Hospital, Egypt \\ ${ }^{4}$ Tropical Medicine, Faculty of Medicine, Port Said University;_Egyptian Liver Research Institute and Hospital, Egypt \\ 5 Internal Medicine Department, Faculty of Medicine, Mansoura University. CEO of the Egyptian Liver Research Institute and Hospital
}

III ABSTRACT

Background: A significant number of patients with hepatitis $\mathrm{C}$ virus (HCV) infection are at high risk of progressing to liver cirrhosis and hepatocellular carcinoma (HCC). The lack of noninvasive methods for assessment of the degree of liver damage is the main limitation in the clinical management of liver diseases. Aim: This study was conducted to evaluate the expression level of plasma miR-500 in HCV-induced fibrosis, cirrhosis and HCC patients. Methods and results: This prospective study involved 120 subjects, who were divided into 4 groups ( $n=30 /$ group): healthy control, liver fibrosis patients, liver cirrhosis patients and HCC patients; all patients encountered in the work were clinically diagnosed as chronic HCV patients. The expression of miR-500 in plasma was asessed using quantitative real-time PCR, whereas serum alpha-fetoprotein (AFP) was measured using electrochemiluminescence immunoassay. Results: The fold change in expression of plasma miR500 showed significant up-regulation in cirrhotic patients more than 8 fold change as compared to fibrosis group. No significant fold changes in plasma miR-500 expression were found between either (HCC versus cirrhosis group) or (HCC versus fibrosis group. The serum level of AFP was 28.09 higher in the HCC group than nonHCC group. Receiver operating characteristic curve (ROC) analysis indicated that the ideal cut-off values of the plasma miR-500 in both fibrosis and cirrhosis groups were 1.52 and 1.15 , respectively and 8.2 and 4.55, respectively for AFP. Conclusion: Plasma miR-500 can be used as a novel biomarker for the differentiation between liver fibrosis and cirrhosis.

Keywords: Biomarkers; Hepatocellular carcinoma; Liver cirrhosis; Liver fibrosis; MicroRNA-500

Editor-in-Chief: Prof. M.L. Salem, PhD - Article DOI: 10.21608/jcbr.2020.39544.1062

\section{ARTICLE INFO}

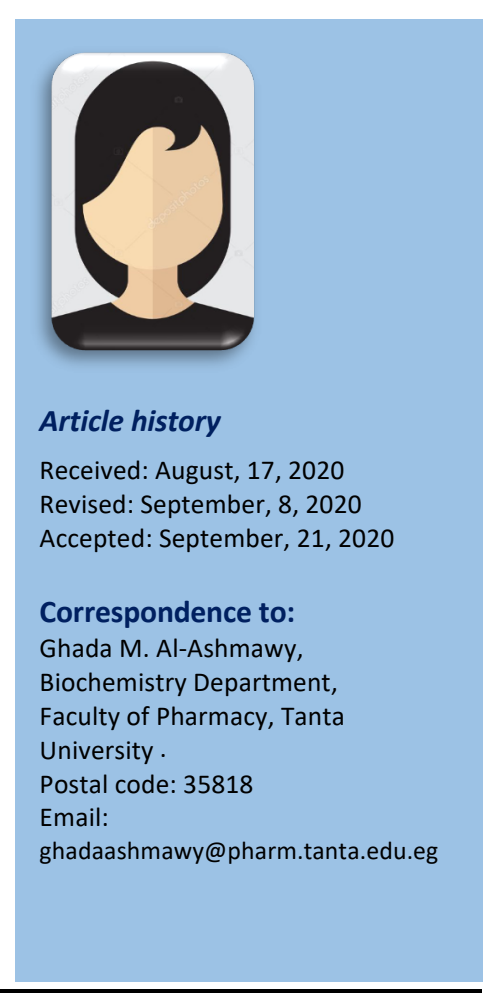

\section{INTRODUCTION}

Hepatitis C virus (HCV) infection is a health disaster disturbing among 185 million individuals universally. Egypt has the topmost frequency for chronic HCV infection worldwide. HCV infected subjects constitute from $10 \%-30 \%$ would progress to more worsening pathogenesis such as cirrhosis and/or HCC (Shepard et al., 2005). Existing biomarkers for diagnosis of liver pathogenesis are lacking both sensitivity and specificity. It is mandatory to develop reliable biomarkers that are sensitive, specific, and non-invasive for early diagnosis and rapid intervention of hepatic fibrosis, cirrhosis and HCC to increase the survival rate of patients. Circulatory microRNAs (miRs) constitute great attention as promising biomarkers for various diseases (Kim et al., 2016). Small non-coding RNA sequences, known as microRNAs (miRNAs), are 18-25 nucleotides. MiRNAs can posttranscriptionally regulate different cellular pathways including cellular differentiation, growth, proliferation, metabolism, angiogenesis, regeneration, survival, apoptosis, and tumorigenesis. Most miRNA genes are located on intergenic regions (non-coding regions) of the nuclear DNA and are expressed in the cytoplasm through the 
following process. In the nucleus, RNA polymerase II transcribes a long primary miRNA (pri-miRNA) with a hairpin-like structure. Drosha then converts it to precursor miRNA (pre-miRNA), a 70- nucleotide stem loop, followed by its transport to the cytoplasm through the action of Exportin 5, where it meets Dicerand is cleaved into 22-nucleotide doublestranded miRNAs. Then, it is separated into two single-stranded miRNAs. The sense (passenger) strand is degraded while the antisense (guide) strand binds to RNA-induced silencing complex (RISC). The interaction between the $5^{\prime}$ seed sequence of the miRNA and the $3^{\prime}$-untranslated region of the mRNA determines the effect of the miRNA, whether degradation of the mRNA or the inhibition of its translation (Elfar et al., 2019).

MiRNAs depending on their inhibited targets can be either tumor-suppressing or oncogenic. Meaningly, miR-21 causes stimulation, proliferation and cell invasiveness while inhibiting apoptosis. MiRNA expression is associated with clinical and biological characteristics of tumors, such as tissue of origin, differentiation, invasiveness and treatment responsiveness. MiRNAs can be utilized as diagnostic markers in human serum or plasma measurements. Thus, cancer and tumor miRNAs in serum or plasma can be measured noninvasively, excluding leukemias which is easily accessible to malignant cells (Babaei et al., 2020).

MiR-500 is of great interest in cancer therapies due to its association with various types of cancer, including gastric and prostate cancer (Bao et al., 2018). MiR-500 is an oncofetal miRNA, which is highly expressed in fetal liver, more than in adult normal liver, and aberrantly expressed in HCC tissue (Yamamoto et al., 2009). A study done by Guo et al. Reported that miR-500 may play an important part in the migration and invasion of HCC, and represents a novel therapeutic target for HCC. However, the precise biological effects of miR-500 in HCC are yet to be determined (Guo et al., 2017).

This study was undertaken in order to investigate miR-500 expression in HCV-infected patients with fibrosis, cirrhosis and HCC and to determine if the miR-500 could be used as novel biomarkers for diagnosis of several stages of $\mathrm{HCV}$-associated liver diseases as an alternative to existing biomarkers.

\section{SUBJECTS AND METHODS Patients}

Ninety HCV-infected Egyptian patients were involved in the research. The patients included 55 males and 35 females, and; their ages ranged from 22 to 71 years. A Prospective randomized double-blinded study was carried out and the patients were recruited from the Egyptian Liver Research Institute and Hospital (ELRIAH) in Sherbin, Mansoura, Egypt during the period from May 2016 to September 2017. Exclusion criteria included pregnancy, cancer therapy (radiotherapy, chemotherapy and immunosuppressive therapy), renal disorders (serum creatinine concentration $>1.5 \mathrm{mg} / \mathrm{dL}$ ), positive results on tests for human immunodeficiency virus (HIV) and hepatitis B virus (HBV), frequent blood transfusions, heart diseases (ECG abnormalities, ischemic or congestive diseases), muscle disorders, pancreatitis and bilharziasis. Univariate analysis was utilized to measure differences in demographic data among fibrosis, cirrhosis and HCC patients. Data were process using SPSS statistical package version 21, IBM corporation software group, USA. However, the controls were younger than HCC patients $(p<0.001)$. Fibrotic and cirrhotic patients were agematched with HCC patients. The demographic data of the patients are summarized in Table 1.

HCV-infected patients were classified into three groups based on ultrasonographic and elastographic criteria. The stage of fibrosis was diagnosed by FibroScan (Echosens ${ }^{\circ}$, Paris, France) and estimated according to METAVIR scoring, as follows (Wendum et al., 2009): Fibrosis stages were arranged on a $0-4$ scale. A score of 0 (FO) indicated no fibrosis, a score of 1 (F1) was identified as mild to moderate focal areas of fibrosis without septa, a score of 2 (F2) was identified as fibrous extensions of most portal areas, with short fibrous septa, the fibrous spreading of large portal areas with many septa without cirrhosis is scored as F3, and a score of 4 (F4) was categorized by manifested bridging and irregular nodules and definitive cirrhosis. Patients with F0/F1 score of 
liver fibrosis were excluded. Thirty fibrotic patients were diagnosed with fibrosis stage F2/F3 and served as the fibrosis group. Thirty patients with cirrhosis were diagnosed with fibrosis stage F4 and served as the cirrhosis group. Thirty patients with HCC were included, as confirmed by the presence of focal lesions detected by Tomography (PHILIPS ${ }^{\circ}$, U.S.A), who served as the HCC group. The etiology of fibrosis, cirrhosis, and HCC for all patients engaged in this study was chronic HCV infection. Thirty infection-free cases were involved in the study and represented as the control group.

The informed consent forms were signed from all applicants before conduct the study. This research study was authorized by the Ethical Committee of the Faculty of Pharmacy, Tanta University.

This study was conducted in accordance with the World Medical Association's Declaration of Helsinki. It was accepted by the Research Ethics Committee of Tanta University with registration number: PR/CTU/09018. The aim of the study was fully clarified to the cases, and all cases signed an informed consent prior to enrolment in the study. The data were reserved secured and utilized only for purposes of research.

\section{Methods}

A venous blood sample $(8 \mathrm{~mL})$ was collected from each case using a sterile $B D$ vacutainer butterfly needle. Each blood sample was divided into four portions ( $2 \mathrm{~mL}$ each). The first portion was collected in a tube containing $4 \mathrm{mg}$ of potassium-ethylene diamine tetraacetic acid $\left(\mathrm{K}_{2} \mathrm{EDTA}\right)$ for complete blood count $(\mathrm{CBC})$. The second portion was delivered in a tube containing $4 \mathrm{mg}$ of $\mathrm{K}_{2}$ EDTA; plasma was separated after centrifugation and stored in a sterile RNase-free Eppendorff tube at $-80{ }^{\circ} \mathrm{C}$ until analysis of miR-500. The third portion was collected into a citrate-tube, and the plasma was separated for determination of prothrombin time. The fourth portion was collected in a BD vacutainer serum separator tube, and serum samples were separated after centrifugation and stored at $-80{ }^{\circ} \mathrm{C}$ until liver biomarkers were assessed.

\section{Biochemical assays}

$\mathrm{CBC}$ were assayed using automated hematology analyzer (Sysmex ${ }^{\circledR}$ XT-1800i, Japan). Serum aspartate aminotransferase (AST) and alanine aminotransferase (ALT) were assessed spectrophotometrically by the kinetic method (Bergmeyer et al., 1986). The activity of serum gamma glutamyl transferase (GGT) was measured spectrophotometrically using the enzymatic colorimetric method (Szasz, 1969). Serum alkaline phosphatase (ALP) was measured using the colorimetric method (Tietz et al., 1983). Serum albumin was measured by the immunoturbidimetric method (Gentilini et al., 2005). Serum total bilirubin was measured using the colorimetric method (Parviainen, 1997). Serum direct bilirubin was measured according to the diazo method (Westwood, 1991). Prothrombin time was determined by coagulation technique described by Matsumoto et al. (Matsumoto et al., 2014). Serum AFP was measured using an electrochemiluminescence immunoassay (ECLIA) method (Guder et al., 1996). The kits were purchased from Roche Diagnostics (Germany).

\section{RNA isolation, reverse transcription and quantitative real time PCR}

Total RNA (including miRs) was extracted from $\mathrm{K}_{2}$ EDTA blood samples using a miRNeasy Mini Kit (Qiagen ${ }^{\circ}$, USA) according to manufacturer's guidelines. The reverse transcription of total RNA, then quantitative real-time polymerase chain reaction ( $q P C R$ ) were performed. The concentration of RNA was measured by measuring by Nonodrop method using Immuline. By measuring the ratio of absorbance at $260 \mathrm{~nm}$ and $280 \mathrm{~nm}$ (A260/A280) and this provides an estimate of the purity of RNA with respect to contaminants that absorb in the UV spectrum, such as protein. Pure RNA has an A260/A280 ratio of 1.9-2.1.

First, a reverse transcription miScript II RT Kit, Catalog no. 218161 kit (Qiagen, Germany) was used to reverse transcript the extracted RNA $(200 \mu \mathrm{L})$ into complementary DNA (cDNA). The obtained cDNA was amplified using a TaqMan ${ }^{\circ}$ miR assay kit (Applied Biosystems Inc ${ }^{\circ}$, USA) as described by the manufacturer. The PCR program was customized to begin with an initial activation for $2 \mathrm{~min}$ at $95^{\circ} \mathrm{C}$, then 40 cycles $\left(95^{\circ}\right.$ $\mathrm{C}$ for $15 \mathrm{~s}$ and $60{ }^{\circ} \mathrm{C}$ for $\left.60 \mathrm{~s}\right)$ using RT-qPCR 
system (DNA technology ${ }^{\circ}$, Russia). Each sample was analyzed and normalized to the level of the reference gene (SNORD 68) and expressed as the relative copy number (RCN). The threshold cycle $(\mathrm{Ct})$ values of the samples were calculated through DT master software. The relative quantity of each miR-500 to Snord 68 was calculated by using the following equation: $\Delta \Delta \mathrm{Ct}=\Delta \mathrm{Ct}$ (target gene) - $\Delta \mathrm{Ct}$ (reference gene) (Guan et al., 2016).

The sequence of the MiR-500 primers (Invitrogen $\mathrm{CO}^{\circ}$, USA) utilized in RT-qPCR were as following: miR-500a forward reverse transcription primer: $5^{\prime}$-CTC AAC TGG TGT CGT GGA GTC GGC AAT TCA GTT GAG TCT CAC CC-3'; quantitative PCR forward primer: $5^{\prime}$-ACA CTC CAG CTG GGT AAT CCT TGC TAC CTG G-3' and reverse primer: 5'-TGG TGT CGT GGA GTC G-3'. The primer sequence for the housekeeping miRNA SNORD 68 was as following: forward primer, 5'-CTCGCTTCGGCAGCACA-3', reverse primer, 5'-AACGCTTCACGAATTTGCGT-3'.

\section{Statistical Analysis}

The expression levels of plasma miR-500 were analyzed using fold change. Data were processed using SPSS statistical package version 21.0, IBM Corporation Software Group, USA. Quantitative results were examined for normality using one sample KolmogorovSmirnov test.

Qualitative data was presented as frequency and percentage, normally distributed data as mean $\pm S D$, and non-normal distributed data as median and interquartile range (IQR). Chisquare test was used to compare qualitative data, ANOVA was used to compare normally distributed quantitative data while KruskalWallis test was used to compare non-normally distributed quantitative data. Comparison of any two groups was done using Chi-square for qualitative data, student's t-test or normally distributed quantitative data or Mann-Whitney $\mathrm{U}$ test for non-normally distributed quantitative data. Spearman correlation coefficient was used to assess strength and direction of association that exists between two variables. All $p$ values were two-tailed and $p \leq 0.05$ was considered statistically significant. ROC curve was designed to assess the diagnostic values of miR-500 and AFP in different groups.

\section{RESULTS}

The results are summarized in Table 2 . The following variables were found to be normally distributed: Age, Hg, RBCs, WBCs, Plt. The remaining numeric variables were not normally distributed: HCV RNA, ALT, AST, GGT, ALP, Albumin (total, direct), creatinine, uric acid, INR, AFP, miR-500. The activities of ALT, AST and GGT were significantly increased in all patients in the fibrosis, cirrhosis and HCC groups $(P<0.0001)$, in compare with those of the control healthy cases.

The HCC group showed significant elevations in ALP activity by $44 \%$ and $47 \%$ ( $P \leq 0.001)$, in comparison with those of the fibrosis and cirrhosis groups, respectively. The patients in the HCC group showed the lowest serum albumin levels compared to those of the healthy control, fibrosis and cirrhosis groups (by $18 \%$, $17 \%$ and $11 \%$, respectively). The other hepatic biomarkers (total bilirubin and INR) were significantly increased in the cirrhosis and HCC groups, when compared to control healthy and fibrosis groups. There were no significant changes in the concentrations of uric acid, creatinine and urea among the studied groups.

Analysis of median fold change in the expression level of plasma miR-500 showed that miR-500 level decreased in fibrosis group (0.76) and there was a significant fold increase in the cirrhosis group (8.29) relative to control healthy group (Table 2). Furthermore, results of comparing plasma miR-500 expression level between different studied groups showed that there was statistically significant increase in the miR-500 expression level in the fibrosis group in comparison to liver cirrhosis group ( $P$ value 0.02).

No significant fold changes in plasma miR-500 expression were found between either ( $\mathrm{HCC}$ versus cirrhosis group) or (HCC versus fibrosis group). A non-significant negative correlation was found between mir-500 and AFP in all studied groups (Table 3). Characteristically, receiver operator characteristic (ROC) analysis was utilized to characterize the ideal cut-off value for the studied diagnostic markers. 
Table 1. Demographic data for patients and healthy controls

\begin{tabular}{|c|c|c|c|c|c|c|c|c|}
\hline \multirow{2}{*}{ Variable } & \multirow{2}{*}{$\begin{array}{l}\text { Healthy } \\
\text { Control } \\
\text { Group } \\
(n=30)\end{array}$} & \multirow{2}{*}{$\begin{array}{l}\text { Fibrosis } \\
\text { Group } \\
(n=30)\end{array}$} & \multirow{2}{*}{$\begin{array}{l}\text { Cirrhosis } \\
\text { Group } \\
(n=30)\end{array}$} & \multirow{2}{*}{$\begin{array}{l}\text { HCC } \\
\text { Group } \\
(n=30)\end{array}$} & \multicolumn{4}{|c|}{ P-value } \\
\hline & & & & & All & $\begin{array}{l}\text { HCC vs. } \\
\text { Fibrosis }\end{array}$ & $\begin{array}{l}\text { HCC vs. } \\
\text { Cirrhosis }\end{array}$ & $\begin{array}{l}\text { Fibrosis } \\
\text { vs. } \\
\text { Cirrhosis }\end{array}$ \\
\hline Age, yr, mean $\pm S D$ & $\begin{array}{c}33.8 \pm \\
7.3\end{array}$ & $48.8 \pm 9.8$ & $\begin{array}{l}56.6 \pm \\
6.02\end{array}$ & $58.3 \pm 7.3$ & $<0.001$ & $<0.001$ & 0.520 & $<0.001$ \\
\hline $\operatorname{Sex}(M: F)$ & $15: 15$ & $16: 14$ & $16: 14$ & 23: 7 & 0.131 & 0.058 & 0.058 & 1.000 \\
\hline Smoking (\%) & 0 & $7(23.3 \%)$ & $10(33.3 \%)$ & $\begin{array}{c}10 \\
(33.3 \%)\end{array}$ & 0.621 & 0.390 & 1.000 & 0.390 \\
\hline DM (\%) & 0 & $3(10.0 \%)$ & $9(30.0 \%)$ & $\begin{array}{c}17 \\
(56.7 \%)\end{array}$ & $<0.001$ & $<0.001$ & 0.037 & 0.053 \\
\hline HTN (\%) & 0 & $3(10.0 \%)$ & $12(40.0 \%)$ & $6(20.0 \%)$ & 0.020 & 0.278 & 0.091 & 0.007 \\
\hline $\begin{array}{l}\text { HCV RNA } \log _{10} \\
\text { IU/mL; median (IQR) }\end{array}$ & Negative & $\begin{array}{c}5.11 \\
(0.89)\end{array}$ & $5.91(1.10)$ & $\begin{array}{c}5.19 \\
(1.49)\end{array}$ & 0.009 & 0.953 & 0.019 & 0.003 \\
\hline $\begin{array}{l}\text { Focal lesion (Single: } \\
\text { Multiple) }\end{array}$ & 0 & 0 & 0 & $16: 14$ & 0.400 & & & \\
\hline Tumor size $(<3 \mathrm{~cm}: \geq 3 \mathrm{~cm})$ & 0 & 0 & 0 & $15: 15$ & 0.870 & & & \\
\hline
\end{tabular}

HCC: Hepatocellular carcinoma; DM: Diabetes mellitus; F: Female; HTN: Hypertension; HCV: Hepatitis C virus; M: Male. Significance was set at a P $\leq$ 0.05 .

Table 2. Biochemical and hematological variables of healthy control and patient groups

\begin{tabular}{|c|c|c|c|c|c|c|c|c|}
\hline \multirow[b]{2}{*}{ Variable } & \multirow{2}{*}{$\begin{array}{l}\text { Healthy } \\
\text { Control } \\
\text { Group } \\
(n=30)\end{array}$} & \multirow{2}{*}{$\begin{array}{l}\text { Fibrosis } \\
\text { Group } \\
(n=30)\end{array}$} & \multirow{2}{*}{$\begin{array}{l}\text { Cirrhosis } \\
\text { Group } \\
(n=30)\end{array}$} & \multirow{2}{*}{$\begin{array}{c}\text { HCC } \\
\text { Group } \\
(n=30)\end{array}$} & \multicolumn{4}{|c|}{ P-value } \\
\hline & & & & & All & $\begin{array}{l}\text { HCC vs. } \\
\text { Fibrosis }\end{array}$ & $\begin{array}{l}\text { HCC vs. } \\
\text { Cirrhosis }\end{array}$ & $\begin{array}{c}\text { Fibrosis } \\
\text { vs. } \\
\text { Cirrhosis }\end{array}$ \\
\hline ALT (U/L), median (IQR) & $19.0(16.0)$ & $\begin{array}{c}42.34 \\
(25.98)\end{array}$ & $\begin{array}{c}41.00 \\
(39.25)\end{array}$ & $\begin{array}{c}51.00 \\
(28.50)\end{array}$ & $<0.001^{*}$ & 0.403 & 0.234 & 0.375 \\
\hline AST (U/L), median (IQR) & $\begin{array}{l}20.00 \\
(8.75)\end{array}$ & $\begin{array}{c}35.39 \\
(17.30)\end{array}$ & $\begin{array}{c}60.50 \\
(45.00)\end{array}$ & $\begin{array}{l}77.00 \\
(37.75)\end{array}$ & $<0.001^{*}$ & $<0.001^{*}$ & $0.029^{*}$ & $0.047^{*}$ \\
\hline GGT (U/L), median (IQR) & $\begin{array}{l}24.50 \\
(12.0)\end{array}$ & $\begin{array}{c}30.82 \\
(17.47)\end{array}$ & $39.0(44.0)$ & $85.0(62.75)$ & $<0.001^{*}$ & $<0.001^{*}$ & $<0.001^{*}$ & 0.119 \\
\hline ALP (U/L), median (IQR) & $\begin{array}{l}68.50 \\
(22.75)\end{array}$ & $\begin{array}{l}72.02 \\
(33.31)\end{array}$ & $\begin{array}{c}64.50 \\
(39.50)\end{array}$ & $\begin{array}{c}99.00 \\
(54.50)\end{array}$ & $0.001^{*}$ & $0.007^{*}$ & $0.002^{*}$ & 0.367 \\
\hline Albumin (g/dL), median (IQR) & $4.40(0.33)$ & $4.31(0.53)$ & $4.20(0.90)$ & $3.59(0.83)$ & $<0.001^{*}$ & $<0.001^{*}$ & $0.004^{*}$ & 0.300 \\
\hline $\begin{array}{l}\text { Total Bilirubin (mg/dL), median } \\
\text { (IQR) }\end{array}$ & $0.50(0.23)$ & $0.60(0.31)$ & $0.75(0.60)$ & $1.20(0.78)$ & $<0.001^{*}$ & $<0.001^{*}$ & $0.003^{*}$ & $0.003^{*}$ \\
\hline $\begin{array}{l}\text { Direct Bilirubin (mg/dL), median } \\
\text { (IQR) }\end{array}$ & $0.10(0.00)$ & $0.24(0.14)$ & $0.28(0.13)$ & $0.50(0.59)$ & $<0.001^{*}$ & $<0.001^{*}$ & $0.001^{*}$ & 0.402 \\
\hline Creatinine (mg/dL), median (IQR) & $0.87(0.21)$ & $0.88(0.50)$ & $0.80(0.20)$ & $0.79(0.27)$ & 0.640 & 0.355 & 0.891 & 0.283 \\
\hline Uric Acid (mg/dL), median (IQR) & $4.85(1.40)$ & $4.85(1.25)$ & $4.75(1.80)$ & $5.25(1.65)$ & 0.527 & 0.290 & 0.482 & 0.784 \\
\hline INR (seconds) & $1.01(0.00)$ & $1.01(0.16)$ & $1.12(0.25)$ & $1.25(0.37)$ & $\begin{array}{c}< \\
0.0001^{*}\end{array}$ & 0.341 & 0.682 & 0.338 \\
\hline AFP, median (IQR) & $2.54(1.98)$ & $4.31(5.25)$ & $\begin{array}{c}6.50 \\
(12.83)\end{array}$ & $\begin{array}{l}28.90 \\
(86.84)\end{array}$ & $<0.001^{*}$ & $<0.001^{*}$ & $0.003^{*}$ & $0.019^{*}$ \\
\hline miR-500, median (IQR) & $1.00(0.00)$ & $\begin{array}{c}0.758 \\
(4.024)\end{array}$ & $\begin{array}{c}8.291 \\
(42.14)\end{array}$ & $\begin{array}{c}1.503 \\
(13.82)\end{array}$ & $0.050^{*}$ & 0.178 & 0.188 & $0.020^{*}$ \\
\hline $\mathrm{Hb}(\mathrm{g} / \mathrm{dL})$, mean $\pm \mathrm{SD}$ & $\begin{array}{c}13.72 \pm \\
1.08\end{array}$ & $\begin{array}{l}13.42 \pm \\
0.77\end{array}$ & $\begin{array}{c}12.83 \pm \\
2.25\end{array}$ & $13.41 \pm 1.63$ & 0.160 & 0.960 & 0.258 & 0.175 \\
\hline $\mathrm{RBCs} \times 10^{3} / \mu \mathrm{L}$, mean $\pm \mathrm{SD}$ & $4.80 \pm 0.47$ & $5.08 \pm 0.53$ & $4.58 \pm 1.07$ & $4.50 \pm 0.70$ & 0.013 & $0.001^{*}$ & 0.742 & $0.027^{*}$ \\
\hline WBCs $\times 10^{3} / \mu \mathrm{L}$, mean $\pm \mathrm{SD}$ & $7.09 \pm 1.95$ & $7.42 \pm 1.95$ & $5.92 \pm 2.60$ & $5.06 \pm 1.58$ & $<0.001^{*}$ & $<0.001^{*}$ & 0.128 & $0.026^{*}$ \\
\hline Plt $\times 10^{3} / \mu \mathrm{L}$, mean $\pm \mathrm{SD}$ & $\begin{array}{c}252.50 \pm \\
52.84\end{array}$ & $\begin{array}{l}194.87 \pm \\
49.70\end{array}$ & $\begin{array}{c}115.36 \pm \\
56.98\end{array}$ & $\begin{array}{c}95.03 \pm \\
37.64\end{array}$ & $<0.001^{*}$ & $<0.001^{*}$ & 0.108 & $<0.001^{*}$ \\
\hline
\end{tabular}

HCC: Hepatocellular carcinoma; ALT: Alanine aminotransferase; AST: Aspartate aminotransferase; ALP: Alkaline phosphatase; GGT: Gamma glutamyl transferase; INR: International normalized ratio; AFP: Alpha-fetoprotein; Hb: Hemoglobin; RBCS: Red blood cells; WBCs: White blood cells; Plt: Platelet.

*: Significance at a P 0.05 . 
First of all, ROC analysis for fibrotic group showed $A U C=1$, and $P<0.0001$ for AFP, while plasma miR-500 failed to do so, with $A \cup C=0.67$ and $\mathrm{P}=0.21$. Furthermore, the calculated cut-off showed that miR-500 had $71.4 \%$ sensitivity, $78.3 \%$ specificity, and $49.6 \%$ accuracy. On the other hand, the AFP ROC curve showed $100 \%$ sensitivity, $100 \%$ specificity, and $100 \%$ accuracy (Figure $1 \mathrm{~A}$ ). On the other hand, ROC analysis bared $A \cup C=0.843$, and $P<0.001$ for AFP which distinguish between $\mathrm{HCC}$ and non-HCC patients, whereas plasma miR- 500 revealed $A \cup C=0.5$ and $\mathrm{P}=0.98$. Moreover, the calculated cut-off showed that miR-500 had $86.7 \%$ sensitivity, $23.3 \%$ specificity, and $55 \%$ accuracy. On the other hand, the AFP ROC curve showed $70 \%$ sensitivity, $86.7 \%$ specificity, and $78.3 \%$ accuracy (Figure 1C).

Table 3. Correlation between miR-500 and AFP in different patient groups

\begin{tabular}{|c|c|c|c|}
\hline Variable Groups & $\begin{array}{c}\text { Fibrosis } \\
n=30\end{array}$ & $\begin{array}{c}\text { Cirrhosis } \\
n=\mathbf{3 0}\end{array}$ & $\begin{array}{l}\mathrm{HCC} \\
\mathrm{n}=\mathbf{3 0}\end{array}$ \\
\hline$r(\mathrm{miR}-500$ and AFP) & -0.016 & -0.064 & -0.058 \\
\hline$P$ value & 0.933 & 0.736 & 0.761 \\
\hline
\end{tabular}

Data are presented as $r$ (Pearson correlation coefficient), HCC: Hepatocellular carcinoma; Alpha-fetoprotein; miR-500: micro RNA-500; Negative correlation.

\section{DISCUSSION}

The prevalence of HCC is increased globally. It is the second most common reason of cancer death worldwide in males and the fifth most common cause of cancer-related death worldwide in females (Gomaa et al., 2014). In Egypt, which has the greatest incidence of HCV worldwide, HCC is the most common cancer (Gomaa et al., 2014). MiRs can be used as a diagnostic biomarker for several diseases. For example, overexpression of miR-205 and miR21 in ductal adenocarcinoma has been reported to precede phenotypic changes in the ducts (Du Rieu et al., 2010), supporting the possibility to use them for early detection of cancers. In addition, a study interrogated plasma miR-10b and miR-373 levels, which are mediators of metastasis in breast cancer, and they uncovered association of these miRNAs for detecting the lymph node metastasis, thereby showing potential as prognostic biomarkers (Chen et al., 2013).
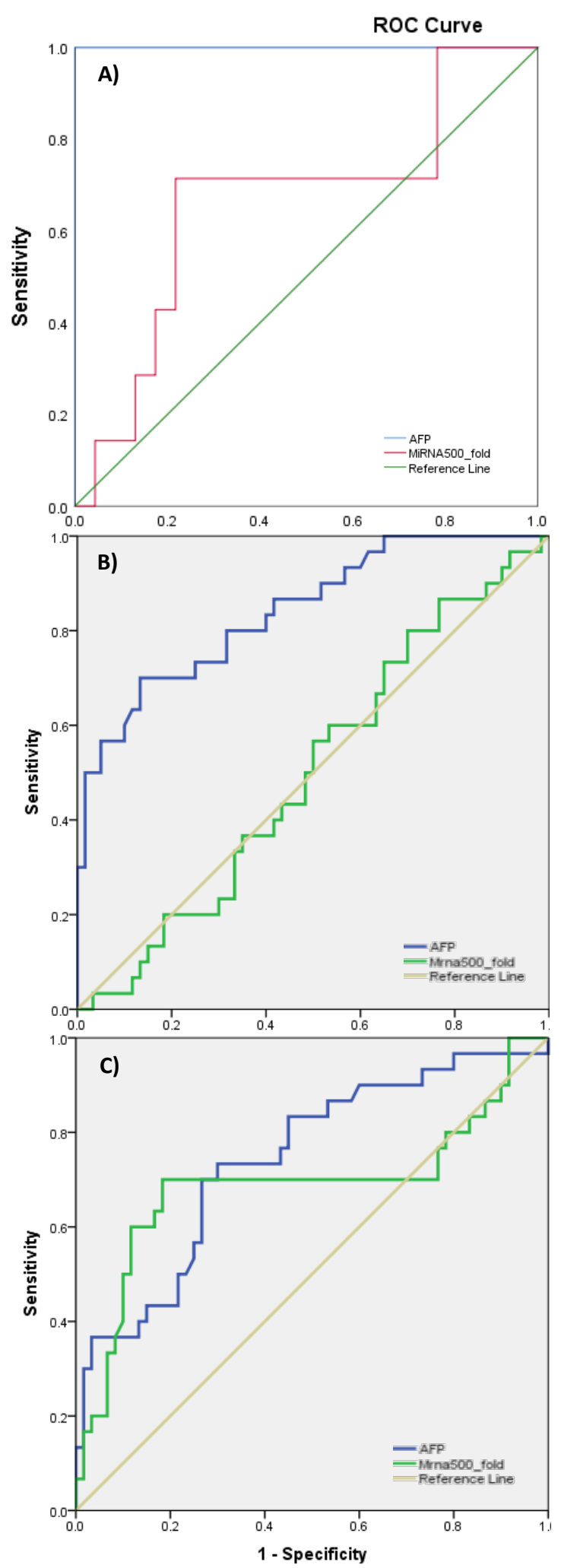

Figure 1. Receiver operating characteristics (ROC) curve comparing the specificity versus sensitivity of microRNA500 and AFP. (A) Fibrosis group, (B) Cirrhosis group, (C) HCC group. Se: Sensitivity; Sp: Specificity; PPV: Positive predictive value; NPV: Negative predictive value, AUROC: Area under the ROC curve, $\mathrm{Cl}$ : Confidence interval, Sig: Significant level P-value, AFP: Alpha-fetoprotein. 
The miRNAs have emerged as a powerful biomarker of hepatic diseases. The miR-122 is major miRNA in liver accounting up to $70 \%$ of the total hepatic miRNAs. The levels of miR-122 can also be correlated with the stage and severity of HBV and HCV infection and are also helpful in the measurement of treatment response (Köberle et al., 2013). The expression levels of 4 miRNAs (miR-122, miR-134, miR-424$3 p$, and miR- 629-5p) were up-regulated during HCV infection (Zhang et al., 2015).

Regarding HCC, Various studies have reported the up-regulation of miR-21, miR-221 and miR222 while down-regulation of miR-122a, miR145, miR-199a and miR-223 in HCC in comparison to the normal tissue in human (Musaddaq et al., 2018).

MiRs are stable and resist degradation by RNase (Cancer, 2012). In various liver diseases, miRs can be considered to be promising biomarkers for diagnosis (Chuanchao et al., 2012). This study was done using the plasma level of circulating miR-500 as a diagnosing marker in detecting liver fibrosis, cirrhosis or HCC. The aim of the current study was to evaluate the expression level of plasma miR-500 in fibrosis, cirrhosis and HCC patients infected with HCV and to compare the plasma level of miR-500 and serum concentration of AFP in different patient groups. The results revealed that cirrhotic samples had significantly increased levels of miR-500 compared to healthy controls and fibrotic patients. Analysis of ROC curve demonstrated that miR-500 had better performance than AFP in distinguishing cirrhotic patients from fibrotic patients (AUROC: 0.688 versus 0.67 , sensitivity: $70.0 \%$ versus $71.4 \%$, specificity: $81.7 \%$ versus $78.3 \%$, significance: 0.004 versus 0.212 , respectively). AFP was more effective than plasma miR-500 in diagnosing of HCC (AUROC: 0.843 versus 0.501, sensitivity: $70.0 \%$ versus $86.7 \%$, specificity: $86.7 \%$ versus $23.3 \%$, significance: $<0.001$ versus 0.986 , respectively). MiR-500 showed no advantage over AFP in diagnosing HCC. Based on these results, we discovered that plasma miR-500 is a novel biomarker of liver cirrhosis. Plasma miR500 is considered an independent diagnostic biomarker as non-significant correlation was found between mir-500 and AFP in fibrotic, cirrhotic and HCC patient groups ( $P$ value: 0.933 , $0.736,0.761$, respectively).

There was some age and sex-relations with the development of HCC and HCV in the Egyptian patients. The age of the studied HCC cases was $58.3 \pm 7.3$ years. This finding was agreed with a study conducted by Holah et al., who reported that the age of $\mathrm{HCC}$ patients fluctuated from 42 to 70 years (mean $58.70 \pm 5.76$ years) (Holah et al., 2015). These findings can be explained by the long time from the beginning of the hepatic inflammatory process to the occurrence of HCC. The majority of HCV infections among Egyptian individuals aged 30 years and older can be explained by parenteral therapy and other iatrogenic exposures [30]. Our study showed that there were $23(76.67 \%)$ males and 7 (23\%) females in the HCC group. This finding is consistent with the study performed by EL Zayadi et al. who found that HCC was significantly more frequent in males than females $(77.7 \%$ and $23.3 \%$, respectively) (ElZayadi et al., 2001). The precise reason for this male predominance is not known, but it may be elucidated by higher contact of males to different environmental carcinogenic factors (aflatoxins, agricultural pesticides, bilharziasis and anti-bilharzial injection treatment), or by greater DNA production in male cirrhotic cases than in females due to the role of sex hormones (Darbari et al., 2003).

Regarding to smoking history, the difference between the studied groups was not significant ( $P$-value $=0.621)$. This finding is consistent with the study performed by Ezzat et al., 2005, who reported that the difference between HCC subjects and controls with regard to history of smoking and alcohol abuse was not statistically significant (Ezzat et al., 2005) This may be related to physicians' advice to stop smoking in presence of liver disease. But this is not agreed with some studies that considered smoking as an independent risk factor for HCC (Koh et al., 2011). The liver metabolizes and transform more than 40 tobacco-related active compounds, in which some considered carcinogens such as polycyclic aromatic hydrocarbons, nitrosamines, and aromatic amines. These tobacco-related carcinogens have been directly implicated in the hepatocarcinogenesis (Koh et al., 2011). 
In the present study, diabetes mellitus (DM) was significantly found in $56.7 \%$ of HCC patients (compared to $10 \%$ among patients with fibrosis and $30 \%$ among patients with liver cirrhosis). The results are in accordance with a metanalysis performed by Wang et al. , which concluded that diabetes is associated with a moderately increased risk of HCC prevalence and HCC mortality (Wang et al., 2012).

By analyzing laboratory biomarkers of our patients, we found a highly significant differences between the patient and control groups regarding liver function tests (albumin, bilirubin, ALT, AST, ALP, GGT), AFP and HCV RNA quantitative $P C R$. These changes may have occurred because HCC is a result of liver cirrhosis consequences, and these parameters are used to stage chronic liver disease. These results run parallel to many studies that concluded that liver cirrhosis is the most important causative factor for the development of $\mathrm{HCC}$, which is present in $80 \%$ to $90 \%$ of $\mathrm{HCC}$ patients (El-Serag, 2012).

Our study focused on the plasma level of circulating miR-500 as a diagnosing marker in detecting the degree of liver damage. The study of Guo et al. (Guo et al., 2017), who revealed that the expression level of miR-500 was higher in the HCC tissues $(n=17)$ compared with the normal liver tissues $(n=7)$ and was closely correlated with poor prognosis suggesting that miR-500 may act as an oncogene in HCC. To overcome the limited sample size performed in previous studies we compared the expression level of plasma miR-500 in larger patient groups. Our study showed that the plasma level of miR500 in HCC cases $(n=30)$ was non-significantly higher (1.503-fold) than that of the normal control group $(n=30)$.

On the other hand, our results exhibited that there is a significant elevation in the expression level of plasma miR-500 in the cirrhotic group, which was 8.291-fold increase relative to the control group with $70.0 \%$ sensitivity, $81.7 \%$ specificity, and $76.7 \%$ overall accuracy. These results were consistent with the results of Yamamoto et al., (Yamamoto et al., 2009), who reported that a significant difference was found in the expression level of miR-500 between normal liver tissues and liver tissues with cirrhosis ( $n=17)$, proposing that the expression of miR-500 was increased during the development stage of cirrhosis.

Also, the level of expression of plasma miR-500 was decreased in fibrotic patients infected with $\mathrm{HCV}$ without cirrhosis, the level of miR-500 was 0.758 -fold difference relative to the healthy control cases with $71.4 \%$ sensitivity, $78.3 \%$ specificity, and $49.6 \%$ overall accuracy. Our results were in accordance with the study performed by Yamamoto et al., (Yamamoto et al., 2009), who found that no significant difference in miR-500 expression was found between normal liver tissues $(n=11)$ and patients infected with HCV without cirrhosis $(n=19)$. Several studies showed different cut-off values of AFP levels in diagnosing patients with HCC, a study conducted on one hundred and thirty nine cases with $\mathrm{HCC}$ with optimum cut-off value of $20.85 \mathrm{ng} / \mathrm{ml}$ showed $72.2 \%$ sensitivity, $86.2 \%$ specificity, $89.9 \%$ positive predictive value, $64.7 \%$ negative predictive value and $77.4 \%$ overall accuracy in diagnosing patients with HCC (Sarwar et al., 2014).

Our results are also supported by the study of Gopal and colleagues, in which a cut-off value of serum AFP greater than $20 \mathrm{ng} / \mathrm{mL}$ had $70.4 \%$ sensitivity and $82.6 \%$ specificity, $76.9 \%$ overall accuracy for HCC detection, AFP level of 59 $\mathrm{ng} / \mathrm{mL}$ or more with $59.6 \%$ sensitivity and $93.9 \%$ specificity, $78.0 \%$ overall accuracy accurately detecting HCC in patients with HCV-associated cirrhosis (Gopal et al., 2014).

There are several limitations in this study including the sample size that was small and needed to be larger. The age of the control group was also required to be matched with the experimental groups. We suggest combining our results with other sero-markers and testing a panel of miRs that could ultimately serve as a reliable diagnostic tests for liver impairment.

\section{CONCLUSION}

Plasma miR-500 could distinguish HCV induced cirrhosis from HCV-associated liver fibrosis and healthy control subjects suggesting their potential usefulness as a promising biomarker for the diagnosis of cirrhosis in HCV-infected patients. It is crucial to authenticate this study in ethnically different populations, with diverse 
genotypes and other risk factors for HCC to survey the real noteworthiness of microRNAs in HCC.

\section{CONFLICT OF INTEREST}

Authors declare that they have no conflicts of interest.

\section{FUDING}

There is no financial support for this study.

\section{REFERENCES}

Babaei K, Shams S, Keymoradzadeh A, Vahidi S, Hamami P, Khaksar R, and Samadani AA (2020). An insight of microRNAs performance in carcinogenesis and tumorigenesis; an overview of cancer therapy. Life Sciences; 240 (November 2019): 117077.

Bao L, Zhang M, Han S, Zhan Y, Guo W, Teng F, and Wang $Q$ (2018). MicroRNA-500a promotes the progression of hepatocellular carcinoma by post-transcriptionally targeting BID. Cellular Physiology and Biochemistry; 47(5): 20462055.

Bergmeyer HU, Horder M, and Rej R (1986). International Federation of Clinical Chemistry (IFCC) Scientific Committee, Analytical Section: approved recommendation (1985) on IFCC methods for the measurement of catalytic concentration of enzymes. Part 3. IFCC method for alanine aminotransferase (L-a. Journal of Clinical Chemistry and Clinical Biochemistry. Zeitschrift Fur Klinische Chemie Und Klinische Biochemie; 24(7). 481-495.

Cancer G (2012). Circulating MicroRNAs: Molecular Microsensors in Gastrointestinal Cancer; 93499362.

Chen W, Cai F, Zhang B, Barekati Z, and Zhong XY (2013). The level of circulating miRNA-10b and miRNA-373 in detecting lymph node metastasis of breast cancer: potential biomarkers. Tumor Biology; 34(1): 455-462.

Chuanchao H, Xu J, Zhang J, Xie D, Ye H, Xiao Z, and Wang J (2012). High expression of trimethylated histone $\mathrm{H} 3$ lysine 4 is associated with poor prognosis in hepatocellular carcinoma. Human Pathology; 43: 1425-1435.

Darbari A, Sabin KM, Shapiro CN, and Schwarz KB (2003). Epidemiology of primary hepatic malignancies in U.S. children. Hepatology; 38(3): 560-566.

Du Rieu MC, Torrisani J, Selves J, Al Saati T, Souque A, Dufresne M, and Buscail L (2010). MicroRNA21 is induced early in pancreatic ductal adenocarcinoma precursor lesions. Clinical Chemistry; 56(4): 603-612.
El-Serag HB (2012). Epidemiology of Viral Hepatitis and Hepatocellular Carcinoma. Gastroenterology; 142(6): 1264-1273.e1.

El-Zayadi A-R, Hanaa M Badran, Barakat EM, Attia ME-D, Shawky S, Mohamed MK, and Saeid A-R (2001). Hepatocellular carcinoma in Egypt: A single center study over a decade Hepatocellular carcinoma in Egypt: A single center study over a decade. Hepatology Research; 19(2): 170-179.

Elfar M, Amleh A, and Ren Z (2019): MiR-590-3p and Its Downstream Target Genes in HCC Cell Lines. Analytical Cellular Pathology; 2019..

Ezzat S, Abdel-Hamid M, Abdel-Latif Eissa S, Mokhtar $\mathrm{N}$, Albert Labib N, El-Ghorory L, and Loffredo CA (2005). Associations of pesticides, HCV, HBV, and hepatocellular carcinoma in Egypt. International Journal of Hygiene and Environmental Health; 208(5): 329-339.

Gentilini F, Dondi F, Mastrorilli C, Giunti M, Calzolari C) Gandini G, and Bergamini PF (2005). Validation of a Human Immunoturbidimetric Assay to Measure Canine Albumin in Urine and Cerebrospinal Fluid. Journal of Veterinary Diagnostic Investigation; 17(2): 179-183.

Gomaa Al, Hashim MS, and Waked I (2014). Comparing Staging Systems for Predicting Prognosis and Survival in Patients with Hepatocellular Carcinoma in Egypt; 9(3): 1-11.

Gopal P, Yopp AC, Waljee AK, Chiang J, Nehra M, Kandunoori $P$, and Singal AG (2014). Factors that Affect Accuracy of $\alpha$-Fetoprotein Test in Detection of Hepatocellular Carcinoma in Patients with Cirrhosis. Clinical Gastroenterology and Hepatology : The Official Clinical Practice Journal of the American Gastroenterological Association; 12(5): 870877.

GUAN C, YANG F, HE X, LI T, YANG Q, HE H, and XU M (2016). Clinical significance of microRNA-155 expression in hepatocellular carcinoma. Oncology Letters; 11(2): 1574-1580.

Guder WG, Narayanan S, Wisser H, and Zawta B (1996). List of Analytes; Preanalytical Variables. Brochure in: Samples: From the Patient to the Laboratory. Darmstadt: GIT Verlag; 11.

Guo Y, Chen L, Sun C, and Yu C (2017) MicroRNA500 a promotes migration and invasion in hepatocellular carcinoma by activating the Wnt/beta-catenin signaling pathway. Biomedicine and Pharmacotherapy= Biomedecine and Pharmacotherapie; 91:1320.

Holah NS, El-azab DS, Aiad HA, and Sweed DM (2015). Hepatocellular carcinoma in Egypt: epidemiological and histopathological properties; 28: 718-724. 
Kim JU, Shariff MIF, Crossey MME, Gomez-Romero M, Holmes E, Jane Cox I, and Taylor-Robinson SD (2016) Hepatocellular carcinoma: Review of disease and tumor biomarkers. World Journal of Hepatology; 8(10): 471-484.

Köberle V, Kronenberger B, Pleli T, Trojan J, Imelmann E, Peveling-Oberhag J, and Waidmann O (2013) Serum microRNA-1 and microRNA-122 are prognostic markers in patients with hepatocellular carcinoma. European Journal of Cancer; 49(16): 34423449.

Matsumoto T, Nogami K, and Shima M (2014) Coagulation function and mechanisms in various clinical phenotypes of patients with acquired factor $V$ inhibitors. Journal of Thrombosis and Haemostasis; 12(9): 15031512.

Musaddaq G, Shahzad N, Ashraf M, and Arshad M (2018) Circulating liver-specific microRNAs as non-invasive diagnostic biomarkers of hepatic diseases in human. Biomarkers; 24: 1-23.

Parviainen MT (1997) A modification of the acid diazo coupling method (Malloy-Evelyn) for the determination of serum total bilirubin. Scandinavian Journal of Clinical and Laboratory Investigation; 57(3): 275-9.

Sarwar S, Khan AA, and Tarique S (2014) Validity of alpha fetoprotein for diagnosis of hepatocellular carcinoma in cirrhosis. Journal of the College of Physicians and Surgeons Pakistan; 24(1): 18-22.

Shepard CW, Finelli L, and Alter MJ (2005) Global epidemiology of hepatitis $C$ virus infection. The Lancet. Infectious Diseases; 5(9): 558-567.

Szasz G (1969) A kinetic photometric method for serum gamma-glutamyl transpeptidase. Clinical Chemistry; 15(2): 124-136.
Tietz NW, Rinker AD, and Shaw LM (1983) IFCC methods for the measurement of catalytic concentration of enzymes Part 5. IFCC method for alkaline phosphatase (orthophosphoricmonoester phosphohydrolase, alkaline optimum, EC 3.1.3.1). Journal of Clinical Chemistry and Clinical Biochemistry. Zeitschrift Fur Klinische Chemie Und Klinische Biochemie; 21(11): 731-748.

Wang J, Li J, Shen J, Wang C, Yang L, and Zhang X (2012) MicroRNA-182 downregulates metastasis suppressor 1 and contributes to metastasis of hepatocellular carcinoma. BMC Cancer; 12(1): 227.

Wendum D, Lacombe K, Chevallier M, Callard P, Valet F, Miailhes P, and Girard P-M (2009) Histological scoring of fibrosis and activity in HIV-chronic hepatitis B related liver disease: performance of the METAVIR score assessed on virtual slides. Journal of Clinical Pathology; 62(4): 361-363.

Westwood A (1991) The Analysis of Bilirubin in Serum. Annals of Clinical Biochemistry: An International Journal of Biochemistry and Laboratory Medicine; 28(2): 119-130.

Yamamoto Y, Kosaka N, Tanaka M, Koizumi F, Kanai Y, Mizutani T, and Ochiya T (2009) MicroRNA500 as a potential diagnostic marker for hepatocellular carcinoma. Biomarkers; 14(7): 529-538.

Zhang S, Ouyang X, Jiang X, Gu D, Lin Y, Kong SK, and Xie W (2015) Dysregulated serum microRNA expression profile and potential biomarkers in hepatitis $\mathrm{C}$ virus-infected patients. International Journal of Medical Sciences; 12(7): 590-598. 


\section{Egyptian Association for Cancer Research (EACR)}

http://eacr.tanta.edu.eg/

EACR is an NGO society that was declared by the Ministry of Social Solidarity (Egypt) No. 1938 in 19/11/2014 based on the initiative of Prof. Mohamed Labib Salem, the current Chairman of EACR. EACR aims primarily to assist researchers, in particular young researchers in the field of cancer research through workshops, seminars and conferences. Its first international annual conference entitled "Anti-Cancer Drug Discovery" was successfully organized in April 2019 (http://acdd.tanta.edu.eg). Additionally, EACR aims to raise the awareness of the society about the importance of scientific research in the field of cancer research in prediction, early diagnosis and treatment of cancer. EACR is also keen to outreach the scientific community with periodicals and news on cancer research including peer-reviewed scientific journals for the publication of cutting-edge research. The official scientific journal of EACR is "International Journal of Cancer and biomedical Research (IJCBR: https://jcbr.journals.ekb.eg) was successfully issued in 2017 and has been sponsored by the Egyptian Knowledge Bank (EKB: www.ekb.eg).

\section{EACR Chairman,}

Prof. Mohamed Labib Salem, PhD

Professor of Immunology

Faculty of Science, Tanta Universiy, Egypt 


\section{GUIDE FOR AUTHORS}

Publisher :The International Journal of Cancer and Biomedical Research (IJCBR) is an International and interdisciplinary journal of preclinical and clinical studies in the area of cancer and biomedical research. It is a peer-reviewed journal in English, published quarterly (in March, June, September, and December) by the Egyptian Association for Cancer Research (EACR) in both print and online formats (4 issues making a volume). Special issues or supplements may also be produced from time to time upon agreement with the Editorial Board.

Scope :The main aim of IJCBR is to attract the best research in animal and human biology in health and diseases from across the spectrum of the biomedical sciences at the molecular, cellular, organ, and whole animal levels especially those that are related to cancer research, including causes, prediction, diagnosis, prognosis, and therapy.

Publication Fees :The journal does charge for submission, processing, or publication of manuscripts (2000 LE for Egyptians or $250 \$$ for non-Egyptians; EACR members receive 15\% discount on publication). Of them Peer-review fees (300 LE) should be paid on submission (non-refundable). For the fast-track production of the accepted manuscript, another 500 LE is paid.

General specifications for different types of article

- Submitted manuscripts should not have been published previously, except in a limited form (e.g. short communication to a symposium or as part of MSc or PhD theses) and should not be under consideration for publication by other journals.

- All co-authors should agree with the content of the manuscript. Authors must have obtained permission to use any copyrighted material in the manuscript before submission.

IJCBR publishes different types of articles

- Original Article (6000 words with $\mathbf{4}$ tables and $\mathbf{4}$ figures, maximum $\mathbf{8}$ display items): Articles with novel findings are the target of IJCBR. Articles presenting a detailed description of a new technique, comparison of existing methods, meta-analyses with comprehensive and in-depth discussion are considered. Papers in a numbered series are not accepted unless all are submitted at the same time.

- Short communications or case study (3000 words with $\mathbf{4}$ display items): Short communications present exceptionally exciting, novel or timely contents are considered. They will be peer-reviewed in the same way as research papers. The references are restricted to 15 .

- Reviews or systematic review (9000 words with $\mathbf{1 0}$ display items): They are invited by the Editorial Board or unsolicited. Review articles have to be contemporary and comprehensive and add information to the knowledge. Sharp critical analyses of novel data or concepts are encouraged. When relevant, a statistical analysis of data and a meta-analysis approach are recommended.

- Opinion papers, letter to the editor or comment to the editor (1500 words with $\mathbf{2}$ display items): They are submitted by invitation of the Editorial Board. They are short papers, which aim to inform scientists, industry, and the public and policymakers about cutting-edge issues in research or the impact of research. They reflect the opinion of their authors who bear full responsibility of the published paper. The references are restricted to 10 .

- Conference/Symposium papers: The journal will consider for publication the results of original work and critical reviews that are presented at conferences/symposia. Symposium organizers who wish to publish bundles of papers from a symposium/conference in IJCBR should first contact the Editor-in-Chief of the IJCBR (EACR@unv.tanta.edu.eg) for agreement. Supplementary material can be proposed and will be made available online. The responsibility for the preparation of a paper in a form suitable for publication lies with the author.

- Thesis: IJCBR can publish the summary and abstract of Master and PhD theses in a special issue.

English: Good quality of written English is required. Spelling may be in British or American English but must be consistent throughout the paper. Care should be exercised in the use of biological terminology that is ill-defined or of local familiarity only. We recommend that authors have their manuscripts checked by an English language native speaker before submission.

Manuscript layout: Manuscripts should be prepared using a standard word processing program and presented in a clear readable format with easily identified sections and headings. The manuscript layout is based on the following directions.

- The main text contains Title, Abstract, Keywords, Introduction, Material and Methods, Results, Discussion, References, Tables, figures.

- The title needs to be concise and informative. Use bold, with an initial capital for the first word only and for words that ordinarily take capitals.

- Short (running) title (max 80 characters including spacing).

- The article text should be typed with double line spacing with wide margins $(2.5 \mathrm{~cm})$.

- The lines must be continuously numbered; the pages must also be numbered.

- Font Calibri 12 should be used for the text, and 12 for the tables, figure legends and references.

- The sections should typically be assembled in the following order:

- Title page contains title, authors' names, full affiliations, acknowledgements and the corresponding author's contacts and Short title.

Abstract (max 250 words, single paragraph): The abstract should be complete and understandable without citation, references, table, or figure. Use structured abstract: Background, Aim, Materials \& Methods, Results and Conclusion. The context and the rationale of the study are presented succinctly to support the objectives. The experimental methods and main results are summarized but should not be overburdened by numerical values or probability values. The abstract ends with a short and clear conclusion. 
Keywords: Up to five short and specific keywords should complement the title with respect to indicating the subject of the paper in alphabetic order.

Introduction: The introduction briefly outlines the context of the work, presents the current issues that the authors are addressing and the rationale to support the objectives, and clearly defines the objectives.

Material and methods: Material and methods should be described in sufficient details so that others can repeat the experiment. Reference to previously published work may be used to give methodological details, provided that said publications are readily accessible and in English. The code of ethics should be followed for all experiments use animals or human samples.

Statistical analysis of results: The statistical design and the models of statistical analysis must be described, as well as each of the statistical methods used. Sufficient statistical details must be given to allow replication of the statistical analysis. The experimental unit should be defined (e.g., individual or group of animals).

Results: Data are presented as tables and figures. Brief description of the results for each table and figure should be presented. Unpublished data can be mentioned when necessary.

Discussion: Should be separate from the Results section and should focus only on intra- and inter-data discussion (the data in the results section) as well as with the relative data in the literature. Don't repeat information already presented in the Introduction section. Start the first paragraph in the Discussion with a paragraph stating the rationale behind the study, the objectives, and the main findings. End Discussion with a short conclusion.

Acknowledgements: In this section, the authors may acknowledge (briefly) their support staff.

Conflict of interest: All papers with a potential conflict of interest must include a description/explanation in a separate heading.

Funding details: The authors should state the source of findings of the study (with research funder and/or grant number). If no fund, the authors should state that the study is self-funded.

\section{References}

Citation of references: In the text, references should be cited by the author(s) surname(s) and the year of publication (e.g. Salem, 2020). References with two authors should be cited with both surnames (e.g. Salem and Meshrif, 2021). References with three or more authors should be cited with the first author followed by et al. (in italics; e.g. Salem et al., 2021). Names of organizations used as authors (e.g. Food and Drug Administration) should be written out in full in the list of references and on the first mention in the text. Subsequent mentions may be abbreviated (e.g. FDA).

- List of references. Literature cited should be listed in alphabetical order by authors' names. It is the author's responsibility to ensure that all references are correct. All authors should be written and so the full journal name.

- $\quad$ References from journal articles are formatted in APA as this example: Al-Amoudi WM (2018). Toxic effects of Lambdacyhalothrin on the rat thyroid. Involvement of oxidative stress and ameliorative effect of ginger extract. Toxicology Reports, 5: 728-736.

- $\quad$ References from books or official reports are formatted as this example. Kebreab E, Dijkstra ANM, Bannink A, Gerrits WJJ, \& France J (2006). Nutrient digestion and utilization in farm animals. CABI Publishing. Wallingford, UK.

- References from chapters or parts of books are formatted as this example. Nozière $P, \&$ Hoch $T$ (2006). Modelling fluxes of volatile fatty acids from rumen to portal blood. In: Nutrient digestion and utilization in farm animals (Kebreab E, Dijkstra ANM, Bannink A, Gerrits WJJ \& France J, eds.), pp. 40-47. CABI Publishing. Wallingford, UK.

Tables: The data should be presented in tables or in graphs, not both.

- Each table should be placed on a separate page at the end of the main text.

- Tables are numbered consecutively using Arabic numbering. They are referred to as Table 1 , Table 2, etc., with capital ' $T$ ', no italics

- $\quad$ Each table has its explanatory caption. The caption is sufficient to permit the table to be understood without reference to the text.

- Abbreviations used in tables/figures have to be defined either as footnotes or in the caption.

\section{Figures}

- $\quad$ Package the figures in a single PowerPoint file. Each figure in a separate slide.

- Figure size should be readable in a width of approximately 8-175 $\mathrm{mm}$ (i.e. the maximum size of printing over two columns).

- Ensure that the font size is large enough to be readable at the final print size, use Calibri font to ensure that they are consistent throughout the figures.

- $\quad$ The figures should preferably be provided as TIFF or EPS files.

- The resolutions of figures must be at least $300 \mathrm{dpi}$.

- Preparation of images for a manuscript: For guidance, we refer to the Journal of Cell Biology's instructions to authors (http://jcb.rupress.org/site/misc/ifora.xhtml\#image_aquisition).

- If a cropped image is included in the main text of a paper (e.g. a few lanes of a gel), display the full original image, including the appropriate controls, the molecular size ladder and/or the scale as relevant, as a single figure in a Supplementary Material file to facilitate peer-review and for subsequent online publication.

- Supplementary material is submitted along with the main manuscript in a separate file and identified at uploading as "Supplementary File - for Online Publication Only" The title of the article is included at the top of the supplementary material.

Corresponding author's guidelines: Upon acceptance the corresponding author is required to send his/her recent formal photo to be attached to the front page of the article. 


\title{
International Journal of Cancer \& Biomedical Research
}

(IJCBR) Online ISSN 2682-2628

\author{
Editor-in-Chief \\ Mohamed Labib Salem, PhD \\ Tanta University, Egypt
}

\begin{tabular}{l} 
EACR Board \\
\hline Nehal Elmashad, MD \\
Tanta University, Egypt \\
Nabil Mohy Eldin, PhD \\
Kafrelsheikh University, Egypt \\
Doaa Al-Ghareeb, PhD \\
Alexandria University, Egypt \\
Abdel-Aziz Zidan, PhD \\
Damanhour University, Egypt
\end{tabular}

\begin{tabular}{l} 
Managing Editor \\
\hline Wesam Meshrif, PhD \\
Tanta University, Egypt \\
Sohaila Galal, PhD \\
Tanta University, Egypt \\
Production and Contact \\
\hline Hamdi Kandil \\
Tanta University, Egypt \\
Email: ljcbr100@gmail.com
\end{tabular}

\section{Advisory Board}

Alberto Montero, MD

Taussig Cancer Center, Cleveland,

USA

Yi Zhang, MD

Zhengzhou University, China

Mark Robunstein, Ph D

Medical University of South

Carolina, USA

Mohsen Farid, Ph D

Derby University, USA

Natarajan Muthusamy, Ph D

Ohio State University, USA

Hideki Kasuya, MD

Nagoya University, Japan

Sherif El-Khamisy, Ph D

Sheffield University, UK

Mohamed Ghanem, Ph D

Kafr Elshikh University, Egypt

Sayed Bakry, Ph D

Alazhar University, Egypt

Sameh Ali, Ph D

Nationa Liver Institute, Egypt

Gamal Badr, Ph D

Assuit University, Egypt

Nadia Hamdy, Pharm D

Ain Shams University, Egypt

\section{Editorial Board}

\section{Clinical studies}

Hesham Tawfik, MD

Tanta University, Egypt

Mohamed Attia, MD

Tanta University, Egypt

Mohamed Elshanshory, MD

Tanta University, Egypt

Essam Elshiekh, MD

Tanta Cancer Center, Egypt

Rasha Eraky, MD

Tanta University, Egypt

Shaima Abou-Kjatwa, MD

Tanta University, Egypt

Marcela Diaz, MD

Cleveland Clinic Foundation, USA

Mohamed Abou-El-Enein, MD

Charité Universitätsmedizin Berlin,

Germany
Alaa Eldin Almostafa, MD

McGill University, Canada

Olfat Gadallah, MD

Tanta University, Egypt

Nagla Sarhan, MD

Tanta University, Egypt

Naglaa Fathy, Pharm D

Zagazik University, Egypt

Mohamed Salama, MD

Mansoura University, Egypt

Mona Marie, MD

Alexandria University, Egypt

Preclinical studies

Mostafa El-Sheekh

Tanta University, Egypt

El-Refai Kenawy, Ph D

Tanta University, Egypt

Mohamed Noureldin, Ph D

Banaha University, Egypt

Yousry Albolkiny, Ph D

Tanta University, Egypt

Elsayed Salim, Ph D

Tanta University, Egypt

Shengdian Wang, Ph D

Chinese Academy of Sciences,

China

Sabry El Naggar, Ph D

Tnata Univesity, Egypr

Faris Alenzi, Ph D

Prince Sattam bin Abdulaziz

University, KSA

Ibrahim El-Sayed, Ph D

Menoufia University, Egypt

Tarek Aboul-Fadl, Ph D

Assiut University, Egypt

Rabab Khairat, Ph D

National Research Center,

Giza, Egypt

Wael Lotfy, Ph D

Alexandria University, Egypt

Ashraf Tabll, Ph D

National Research Center, Egypt

Nahla Shoukry, Ph D

Suez University, Egypt
Medhat Eldenary, Ph D

Tanta University, Egypt

Azza Hasan, Ph D

Menufia University, Egypt

Nanees Gamal Eldin, Ph D

Tanta University, Egypt

Mohamed Mansour, UK

Sabbah Hammoury, Ph D

Alexandria Ayadi Almostaqba

Oncology Hospital, Egypt

Nehal Aboulfotoh, Ph D

Zewail City for Science and

Technology, Cairo, Egypt

Amir Elkhami, Ph D

Galaxo, San Francisco, USA

Ahmed Alzohairy, Ph D

Zagazi University, Egypt

Wgady Khalil, Ph D

National Research Center, Egypt

Amr Amin, Ph D

United Arab Emirates

University, UAE

AbdelRahman Zekri, Ph D

National Cancer Institute, Egypt

Hussein Khamis, Ph D

Alexandria University, Egypt

Magdy Mahfouz, Ph D

Kafr Elsheikh University, Egypt

Ehab Elbedewey, Ph D

Tanta University, Egypt

Abeer Badr, Ph D

Cairo University, Egypt

Mamdooh Ghoneum, Ph D

Charles Drew University of

Medicine \& Science, USA

Haiam Abou Elela, Ph D

National Institute of Oceanography and Fisherie, Egypt

Maha EL-Demellawi, Ph D City for Scientific Research \&

Technology Applications, Egypt

Desouky Abd-El-Haleem, Ph D

City for Scientific Research \&

Technology Applications, Egypt 